\title{
Coconut Oil Supplementation Does Not Affect Blood Pressure Variability and Oxidative Stress: A Placebo-Controlled Clinical Study in Stage-1 Hypertensive Patients
}

\author{
Francisco A. O. Júnior ${ }^{1}{ }^{(}$, Clara R. Ruiz $^{2}$, Yohanna de Oliveira $^{3}{ }^{\circledR}$, Marco A. V. Barros $^{4}$, Alexandre S. Silva ${ }^{5}{ }^{\circledR}$, \\ Maria S. B. Santos ${ }^{5}$, Vinícius J. B. Martins ${ }^{1} \mathbb{D}$, Camille M. Balarini ${ }^{1}$ and Valdir A. Braga ${ }^{2, *}$ \\ 1 Health Sciences Center, Department of Physiology and Pathology, Federal University of Paraiba, \\ Joao Pessoa 58051-900, Brazil; junior.ltf@gmail.com (F.A.O.J.); viniciusjbmartins@gmail.com (V.J.B.M.); \\ camille.balarini@gmail.com (C.M.B.) \\ 2 Biotechnology Center, Federal University of Paraiba, Joao Pessoa 58051-900, Brazil; \\ clararittmeyer97@gmail.com \\ 3 Health Sciences Center, Department of Nutrition, Federal University of Paraiba, Joao Pessoa 58051-900, Brazil; \\ yoh_0806@hotmail.com \\ 4 Medical Sciences Center, Federal University of Paraiba, Joao Pessoa 58051-900, Brazil; mavivo@cardiol.br \\ 5 Health Sciences Center, Department of Physical Education, Federal University of Paraiba, \\ Joao Pessoa 58051-900, Brazil; alexandresergiosilva@yahoo.com.br (A.S.S.); \\ sbrasileiro@yahoo.com.br (M.S.B.S.) \\ * Correspondence: valdir@cbiotec.ufpb.br; Tel.: +55-83-32167173
}

Citation: Júnior, F.A.O.; Ruiz, C.R.; de Oliveira, Y.; Barros, M.A.V.; Silva, A.S.; Santos, M.S.B.; Martins, V.J.B.; Balarini, C.M.; Braga, V.A. Coconut Oil Supplementation Does Not Affect Blood Pressure Variability and Oxidative Stress: A Placebo-Controlled Clinical Study in Stage-1 Hypertensive Patients. Nutrients 2021, 13, 798. https:// doi.org/10.3390/nu13030798

Academic Editor: Silvio Buscemi

Received: 20 November 2020

Accepted: 24 February 2021

Published: 28 February 2021

Publisher's Note: MDPI stays neutral with regard to jurisdictional claims in published maps and institutional affiliations.

Copyright: (c) 2021 by the authors. Licensee MDPI, Basel, Switzerland. This article is an open access article distributed under the terms and conditions of the Creative Commons Attribution (CC BY) license (https:// creativecommons.org/licenses/by/ $4.0 /)$.
Abstract: Exploring an alternative to improve the clinical management of hypertension, we tested the hypothesis that food supplementation with coconut oil (EVCO), alone or combined with aerobic exercise training, could exert an antihypertensive effect (primary outcome) in patients with stage 1 hypertension. Forty-five hypertensive volunteers of both genders participated in a placebo-controlled clinical trial. The volunteers were submitted to 24-hour ambulatory blood pressure monitoring, analysis of blood pressure variability (BPV), measurement of serum malondialdehyde (MDA) and nutritional assessment. Results indicate that EVCO consumption had no adverse effects. The supplementation did not increase the caloric intake compared with placebo, and the dietary constituents were similar between groups, except for the saturated fats, especially lauric acid. The analysis of blood pressure indicated absence of antihypertensive effect of EVCO alone or combined with physical training. Furthermore, no effects on blood pressure variability and oxidative stress were observed in the supplemented hypertensive patients. Thus, despite the results observed in pre-clinical studies, the current clinical study did not provide evidence to support the use of coconut oil as an adjuvant in the management of hypertension in humans.

Keywords: nutritional approach; cardiovascular system; hypertension; coconut oil

\section{Introduction}

The impact of hypertension on health continues to rise despite the advances in antihypertensive drug development by the pharmaceutical industry. In 2018, data from the American Heart Association indicated that $40.6 \%$ of deaths from cardiovascular disease in the U.S. were related to hypertension [1] and in the year 2035 the costs related to hypertension will exceed 220 billion dollars. Hypertension is a pandemic disease that affects approximately one-third of the world population [2].

Non-pharmacological approaches have been important adjuncts in the treatment of hypertension. Nutritional strategies such as using antioxidants and regular exercise have been shown to be beneficial [3-5], but more consistent clinical evidence is needed to strengthen the role of these alternatives in the management of hypertension. A recent strategy that has been used is the intake of coconut oil due to its nutritional, medicinal and cosmetic uses [6]. 
It has been demonstrated that coconut oil can increase high-density lipoprotein, improving the lipid profile $[7,8]$, and increase main enzymes involved with the redox balance [8-10]. Despite these findings, currently there is controversy over the effects of coconut oil on human health $[11,12]$. In the cardiovascular system, preclinical studies of our group showed that coconut oil supplementation, alone or combined with exercise training, was able to induce antihypertensive response in spontaneously hypertensive rats [13]. In addition, it was shown that this effect was associated with an improvement in baroreflex response and attenuation of oxidative stress. Subsequently, it was found that lauric acid, the main fatty acid isolated from coconut oil, was able to induce a dose-dependent reduction in blood pressure (BP), as well as to promote vasorelaxation of isolated rat superior mesenteric artery [14].

However, there are no reports on the effects of coconut oil supplementation in relation to the cardiovascular system in humans. Studies that focus on the relationship of coconut oil consumption with physiological variables of interest such as BP and BP variability can elucidate the potential of coconut oil as an adjuvant alternative in the clinical management of hypertension. Thus, we tested the hypothesis that coconut oil supplementation, isolated or combined with physical training, could exert antihypertensive effects in patients with stage 1 hypertension.

\section{Materials and Methods}

\subsection{Subjects and Experimental Groups}

Hypertensive patients were recruited to participate in this placebo-controlled study. Patients with stage 1 systemic arterial hypertension (mild hypertension) were included. This degree of hypertension is characterized by levels of systolic blood pressure between 140 and $159 \mathrm{mmHg}$ and/or diastolic blood pressure between 90 and $99 \mathrm{mmHg}$ [15]. Patients were evaluated by 24-hour blood pressure monitoring to confirm the diagnosis of hypertension and for follow-up during the experimental period. The study included patients of both genders with a minimum age of 20 and a maximum age of 64 years. Patients with diabetes mellitus or under pharmacological treatment for hypertension were not included. The study was conducted in accordance with the ethical guidelines of the Declaration of Helsinki and approved by the Research Ethics Committee of the University Hospital of the Federal University of Paraiba, Brazil (protocol $n^{\circ} 1.523 .128 / 2016$ ). Written informed consent was obtained from all volunteers prior to participation. In addition, this clinical protocol was approved in the Brazilian Registry of Clinical Trials ( ${ }^{\circ}$ RBR-5s9bhc).

The sample size was based on the outcome of reduced systolic blood pressure obtained by Perona et al. [16], considering a mean difference of $14 \mathrm{mmHg}$ with a standard deviation of 10 and $8 \mathrm{mmHg}$ for each group. The sample size was calculated with the open license tool at (https: / / www.openepi.com (accessed on 1 February, 2017)) and, as a result, a minimum of seven subjects for each group was obtained, considering a confidence interval of $95 \%$ and a statistical power of $80 \%$. Our study included 51 hypertensive patients who were allocated by simple random distribution (1:1) using a freely available website (www.randomizer.org (accessed on 1 February, 2017)). These patients were followed up in the experimental groups: group supplemented with extra-virgin coconut oil-EVCO; group supplemented with placebo; group supplemented with EVCO plus physical training (EVCO-training); and group supplemented with placebo plus physical training (placebo-training). Six patients did not complete the treatment protocol and were excluded. Two of them were from the EVCO group (one on a physical training protocol and one untrained). The patient in the training group dropped out of the study, and the other patient started pharmacological treatment by decision of the cardiologist on the study team. The remaining four losses were from patients supplemented with the placebo intervention (one from the trained group and three from the untrained group). The patient in the trained group had to move from the study city, and the other three dropped out the study. Considering blood pressure analyzes, two records were excluded (one from the placebo group and one from the EVCO group) because they did not reach more than $80 \%$ of the valid measures after 24 -hour 
monitoring. Thus, we had the following experimental groups: EVCO, $n=14$; Placebo, $n=11$; EVCO-training, $n=11$; and Placebo-training, $n=9$, Figure 1 .

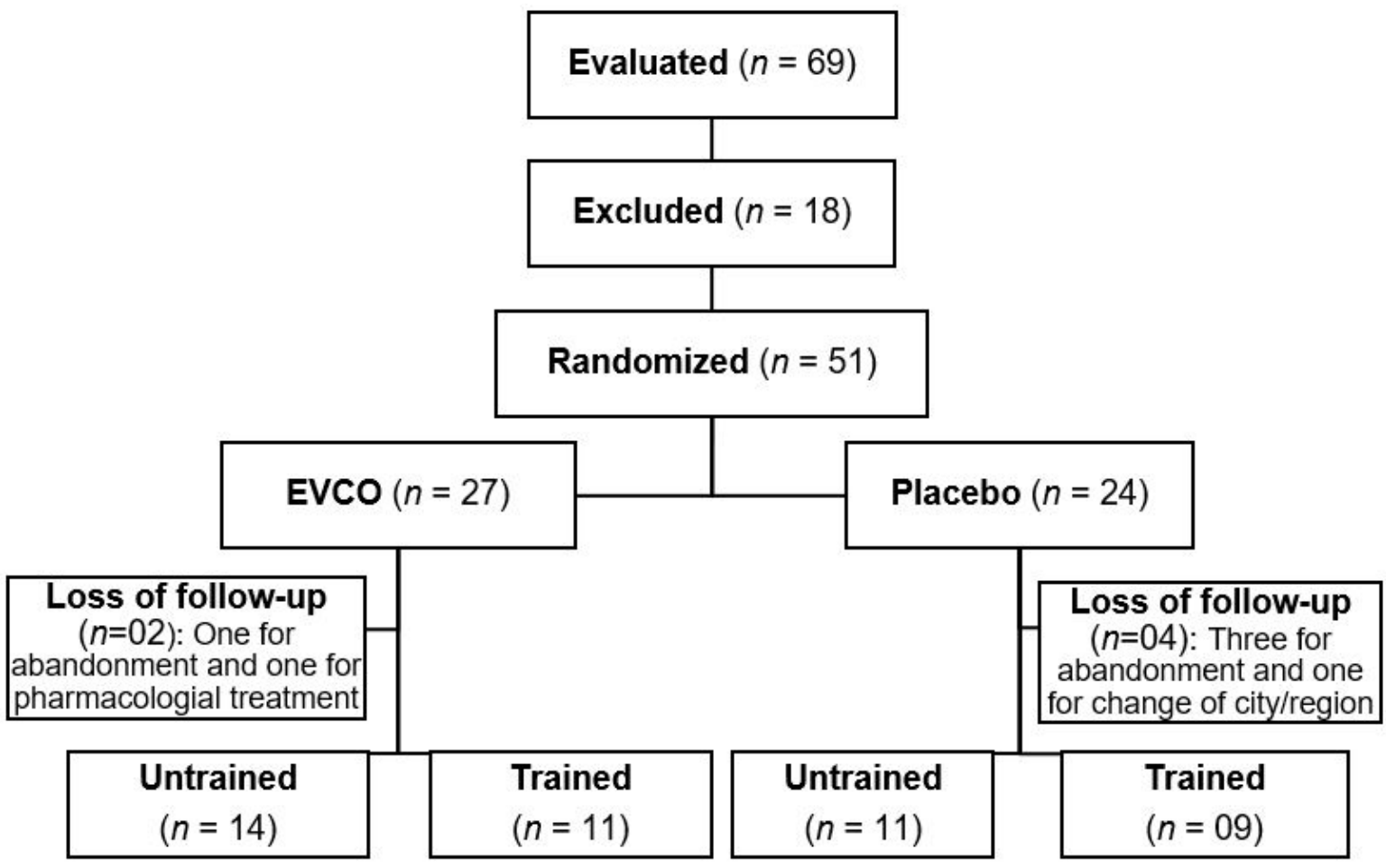

Figure 1. Flowchart of the study design.

\subsection{Study Design and Experimental Protocols}

This is a randomized, single-blinded, placebo controlled clinical trial. Patients were initially submitted to 24-hour ambulatory blood pressure monitoring according to VI Brazilian guidelines for hypertension [15]. Blood collection was performed to biochemical analysis. After the initial evaluation, the patients in each group were submitted to food supplementation with EVCO capsules or placebo for a period of 30 days. Twenty-four hours after the last day of this intervention period, patients were again evaluated for initial variable.

The patients receiving EVCO or placebo were instructed to intake 10 capsules a day within the main meals as follows: three during the breakfast, four during lunch and three during dinner. The EVCO groups received $10 \mathrm{~mL}$ /day (1 mL in each capsule) of EVCO (Cocos nucifera L.) [17]. Both preparations were standardized in a specialized pharmacy (registration with the Ministry of Health $\mathrm{N}^{\mathrm{o}}$. 5.6372.0016.001-4) (Table 1).

Table 1. Nutritional information on coconut oil supplementation.

\begin{tabular}{ccc}
\hline Nutritional Constituents & Quantity & Dv \%* \\
\hline Total calories (Kcal) & 90 & 5 \\
Total fats (g) & 10 & 20 \\
Saturated fats (g) & 7.5 & 35 \\
Monounsaturated fats (g) & 2.5 & $* *$ \\
Lauric acid (g) & 5 & $* *$ \\
Myristic acid (g) & 2.5 & $* *$ \\
Oleic acid (g) & 2.5 & $* *$
\end{tabular}

Equivalent to the content of 10 capsules with extra virgin coconut oil. * Percentages of daily values in relation to a 2000 kcal diet. ${ }^{* *}$ Daily values not established. 
The training protocol consisted of four weeks of aerobic training (walking and/or running on an ergometric treadmill), three times per week, lasting $60 \mathrm{~min}$, of moderate intensity (50\% to $70 \%$ heart rate reserve) [18]. A one mile field test was performed prior to the protocol to estimate the maximum oxygen consumption and to obtain the maximum heart rate [19]. The heart rate of training was determined based on the reserve heart rate [20], monitored by Polar ${ }^{\circledR}$ frequency meter model M200 (Polar Electro, Kempele, Finland), and supervised by rating of perceived exertion [21].

\subsection{Nutritional Evaluation}

The dietary intake of each patient was assessed by a three day food recorder, two representing the weekday diet and one representing the weekend diet. The average food consumption over the three days was used for nutritional assessment. The analysis was performed by a nutrition professional using a nutritional software (Dietwin Plus ${ }^{\circledR}$, version 3048/16, Porto Alegre, Brazil). The nutritional parameters of total energy intake, carbohydrates, total proteins and fats, saturated fatty acids (including lauric acid), unsaturated fatty acids, intake of sodium and antioxidants were selected for analysis.

\subsection{Thiobarbituric Acid Reactive Substances (TBARS) Assay and Clinical Biochemistry Measurements}

To evaluate lipid peroxidation, serum samples were collected to measure levels of malondialdehyde (MDA) determined by TBARS assay [22]. After blood collections, the samples were centrifuged at $5000 \times g$ for $10 \mathrm{~min}$ to obtain serum. Then, $250 \mu \mathrm{L}$ of serum were stored at $37^{\circ} \mathrm{C}$ for $1 \mathrm{~h}$, after which $400 \mu \mathrm{L}$ of $35 \%$ perchloric acid was added, and the mixture was centrifuged $\left(14,000 \times \mathrm{g} / 4^{\circ} \mathrm{C}\right)$ for $20 \mathrm{~min}$. Four hundred and fifty microliters of supernatant was removed and mixed with $0.6 \%$ thiobarbituric acid and incubated at $90{ }^{\circ} \mathrm{C}$ for $1 \mathrm{~h}$. Then, absorbance at $532 \mathrm{~nm}$ was measured. A standard curve was generated using 1,1,3,3-tetrametoxypropane. Results were expressed as nmol/mL.

Serum was used to determine total cholesterol, triglycerides, low density lipoproteins (LDL-cholesterol), high density lipoproteins (HDL-cholesterol) and glucose using colorimetric standardized commercial kits (Blioclin-Quibasa, MG, Brazil). Non-HDL-cholesterol is calculated by subtracting HDL-cholesterol from total cholesterol.

\subsection{Ambulatory Blood Pressure Monitoring [ABPM) for 24 Hours and Anthropometric Measures}

The BP was measured for a period of $24 \mathrm{~h}$ using a Dyna MAPA + Cardios $^{\circledR}$ device (São Paulo, Brazil). The equipment was programmed to perform measurements every 15 min during the waking period and every 30 min during sleep, according to the recommendations of the 4th Guidelines for Ambulatory Blood Pressure Monitoring and 2nd Guidelines for Residential Blood Pressure Monitoring [23]. The data obtained during registration were used to determine the mean values of systolic diastolic blood pressure and mean. In addition, they were also used to establish the parameters of blood pressure variability, standard deviation and average real variability [24]. In addition, patients were weighed and measured using a portable stadiometer ( $1 \mathrm{~mm}$ accuracy) and a body weight apparatus (OMRON ${ }^{\circledR}$ model HBF-514C, Shiokoji Horikawa, Shimogyo-ku, Kyoto, Japan). Body mass index was calculated using the formula weight/(height) ${ }^{2}$.

\subsection{Statistical Analysis}

The analysis of normality was performed by Shapiro-Wilk test. Non-normal variable (malondialdehyde) was log-transformed from their original values. In the nutritional analysis, a comparison between means of the diet components the placebo and EVCO periods was made by unpaired $t$ Student test. For the other analyses, a one-way ANCOVA corrected by age was performed with repeated measurements, followed by Bonferroni post-test. The data were expressed as means and standard deviation and the significance level was adopted with $p<0.05$. The effect size values were expressed by the partial eta square $\left(\eta^{2}\right)$. 


\section{Results}

\subsection{Baseline Profile of Participants}

Table 2 displays the baseline assessment of the patients treated in this study. The patients showed body mass index (BMI) in the overweight range and total cholesterol, triglycerides and non-HDL cholesterol with borderline concentrations.

Table 2. Baseline clinical characteristics.

\begin{tabular}{lccccc}
\hline $\begin{array}{l}\text { Baseline } \\
\text { Parameters }\end{array}$ & $\begin{array}{c}\text { EVCO } \\
(\boldsymbol{n}=\mathbf{1 4})\end{array}$ & $\begin{array}{c}\text { Placebo } \\
(\boldsymbol{n}=\mathbf{1 1})\end{array}$ & $\begin{array}{c}\text { EVCO } \text { plus } \\
\text { Training } \\
(\boldsymbol{n}=\mathbf{1 1})\end{array}$ & $\begin{array}{c}\text { Placebo } \text { plus } \\
\text { Training } \\
(\boldsymbol{n}=\mathbf{9})\end{array}$ & $\boldsymbol{p}$ Valor \\
\hline Men $n(\%) \dagger$ & $7(46.0 \%)$ & $7(63.0 \%)$ & $8(73 \%)$ & $7(88 \%)$ & 0.390 \\
Age (years) & $49.6 \pm 9.9$ & $35.0 \pm 9.3$ & $42.8 \pm 9.0$ & $37.0 \pm 12.3$ & $0.006 \#$ \\
BMI & $29.8 \pm 5.8$ & $28.6 \pm 5.4$ & $27.9 \pm 4.7$ & $31.4 \pm 4.2$ & 0.622 \\
Total cholesterol & $198.6 \pm 36.3$ & $163.2 \pm 36.3$ & $195.0 \pm 48.5$ & $197.1 \pm 85.5$ & 0.433 \\
HDL-cholesterol & $38.9 \pm 12.7$ & $45.7 \pm 13.0$ & $55.2 \pm 10.3$ & $38.4 \pm 12.9$ & $0.009 \#$ \\
LDL-cholesterol & $82.2 \pm 8.8$ & $60.7 \pm 16.1$ & $94.6 \pm 26.2$ & $77.2 \pm 27.9$ & $0.039 \#$ \\
Non-HDL cholesterol & $167.3 \pm 59.3$ & $117.5 \pm 34.9$ & $139.7 \pm 50.1$ & $158.6 \pm 84.4$ & 0.355 \\
Triglycerides & $158.6 \pm 66.2$ & $108.6 \pm 47.0$ & $168.1 \pm 51.3$ & $148.4 \pm 97.2$ & 0.299 \\
Glucose & $89.2 \pm 13.1$ & $82.2 \pm 12.8$ & $90.9 \pm 10.0$ & $89.5 \pm 14.4$ & 0.492 \\
MDA a & $2.29 \pm 0.3$ & $2.18 \pm 0.2$ & $2.65 \pm 0.3$ & $2.16 \pm 0.2$ & $0.012 \#$ \\
SAP b & $134.6 \pm 8.2$ & $131.3 \pm 9.1$ & $134.2 \pm 8.6$ & $132.1 \pm 6.2$ & 0.303 \\
DAP c & $87.7 \pm 8.1$ & $88.8 \pm 9.9$ & $89.9 \pm 6.6$ & $88.0 \pm 4.4$ & 0.898 \\
MAP d & $103.2 \pm 7.2$ & $102.7 \pm 9.0$ & $104.5 \pm 6.2$ & $102.5 \pm 3.3$ & 0.765 \\
SD-MAP & $9.3 \pm 1.6$ & $8.9 \pm 1.9$ & $10.2 \pm 2.2$ & $9.3 \pm 1.9$ & 0.552 \\
ARV-MAP & $6.5 \pm 1.3$ & $6.1 \pm 0.9$ & $6.5 \pm 1.3$ & $6.4 \pm 0.7$ & 0.898 \\
VO ${ }_{2}$ max & - & - & $43.4 \pm 5.7$ & $39.8 \pm 4.6$ & 0.140 \\
\hline
\end{tabular}

$\overline{(H D L)}=$ High Density Lipoprotein; (LDL) = Low-density lipoprotein; others lipidic profile parameters and glucose expressed in $(\mathrm{mg} / \mathrm{dL})$. BMI = Body Mass Index $\left(\mathrm{kg} / \mathrm{m}^{2}\right)$. ${ }^{\text {a }}$ The values of malondialdehyde $(\mathrm{MDA})$ are expressed in $\log (\mathrm{nmol} / \mathrm{mL}) ;{ }^{\mathrm{b}},{ }^{\mathrm{c}}$ and ${ }^{\mathrm{d}}$ Mean values of systolic (SAP), diastolic (DAP) and mean blood pressure (MAP) (mmHg) obtained in awake patients using 24-hour blood pressure monitoring, respectively; and ${ }^{\mathrm{e}}$ Standard deviation (SD) and ${ }^{\mathrm{f}}$ Average real variability (AVR) of the mean arterial pressure $(\mathrm{mmHg}) ;{ }^{\mathrm{g}}\left(\mathrm{VO}_{2} \mathrm{max}\right)=$ Maximum oxygen consumption $\left(\mathrm{mL} \cdot \mathrm{kg}^{-1} \cdot \mathrm{min}^{-1}\right)$ estimated by 1 -mile field test for the patients in the training protocol. Data expressed as mean \pm standard deviation or $\mathrm{n}(\%)$; + Person Chi-square test; \# Significance by ANOVA one-way for group factor and Post Hoc tests(Age: EVCO vs. Placebo $(p=0.008)$ and EVCO vs. Placebo-Training $(p=0.043)$; HDL: EVCO vs. EVCO-Training $(p=0.013)$ and EVCO-Training vs. Placebo-Training $(p=0.026)$; LDL: Placebo vs EVCO-Training $(p=0.013)$; MDA: EVCO vs. EVCO-Training $(p=0.042)$ and EVCO -Training vs. Placebo-Training $(p=0.028)$.

\subsection{Nutritional Analysis of Food Records}

The records obtained from the food diaries of the patients supplemented with coconut oil or placebo indicates that there was no difference in the energy intake (1961 (1700-2222) vs. $1678(1450-1905) \mathrm{kcal} ; p=0.134)$, carbohydrate intake $(252.8(200.1-305.5)$ vs. 213.2 $(177.9-248.4) \mathrm{g} ; p=0.278)$ and total fats intake $(69.1$ (56.7-81.5) vs. $55.7(40.5-70.8) \mathrm{g}$; $p=0.161)$. However, considering the fractions of saturated fats $(29.3(23.5-35.1)$ vs. 18.5 $(12.0-24.8) \mathrm{g} ; p=0.017)$ and the amount of lauric acid $(4.64(4.50-4.77)$ vs. $0.20(0.07-0.34) \mathrm{g}$; $p<0.001$ ) ingested in periods of coconut oil and placebo supplementation, respectively, a greater amount of saturated fats and lauric acid is observed for patients supplemented with coconut oil. For the other dietary constituents evaluated (proteins, cholesterol, linolenic acid, trans fats, sodium, zinc, vitamins B12, B9, A, C, E and $\beta$-carotene) there was no significant difference between the periods of supplementation with EVCO and placebo (data not shown). In addition, no adverse effects (diarrhea, constipation, nausea, colic, migraine, among others) were observed or reported in relation to the use of $10 \mathrm{~mL} /$ day of EVCO during the 30-day period, suggesting that this pattern of dietary supplementation is fully safe in humans. 


\subsection{Analysis of 24-Hour Blood Pressure Monitoring}

Figure 2 shows the mean blood pressure values obtained from the 24-hour blood pressure record of hypertensive patients, before and after the 30-day intervention for all experimental groups. No differences were found.
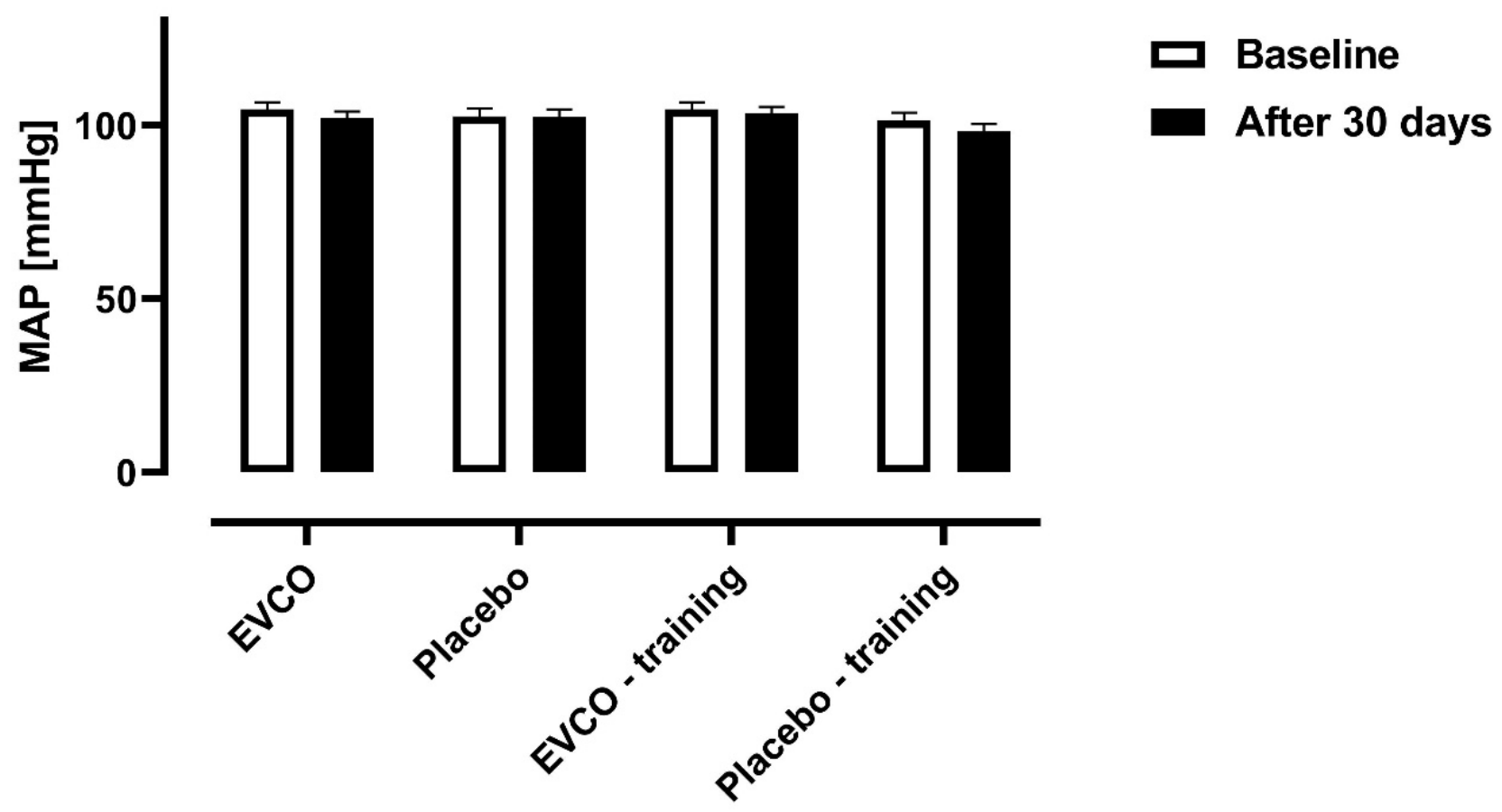

Figure 2. Comparison of mean blood pressure levels between experimental groups. Data expressed as means and SD $(n=43)$. Mean Arterial Pressure (MAP). One-way ANCOVA of repeated measures corrected for age: Time factor $(p=0.119$ and $\left.\eta^{2}=0.063\right)$ and Group factor $\left(p=0.482\right.$ and $\left.\eta^{2}=0.062\right)$. There were no significant interaction of effects $(p=0.446$ and $\left.\eta^{2}=0.067\right)$.

\subsection{Analysis of Serum Concentrations of Malondialdehyde}

There is no EVCO-induced effect on serum MDA concentrations (nmol/mL) assessed after the experimental intervention compared to control intervention (EVCO $(2.22 \pm 0.10$ vs. $2.24 \pm 0.13)$; Placebo ( $2.27 \pm 0.11$ vs. $2.32 \pm 0.15)$; EVCO plus training $(2.63 \pm 0.10$ vs. $2.20 \pm 0.14)$; and Placebo plus training ( $2.21 \pm 0.12$ vs. $2.29 \pm 0.17) ; p=0.644$ and $\eta^{2}=0.009$ ). However, there is an interaction effect between time and group that appears to be promoted as a function of a decrease between initial and final MDA concentrations among patients who were supplemented with EVCO and trained $\left(p=0.015\right.$ and $\left.\eta^{2}=0.227\right)$ (Figure 3).

\subsection{Analysis of Blood Pressure Variability}

The analysis of blood pressure variability data, represented by standard deviation (SD) and average real variability (ARV), showed that supplementation with EVCO was not effective within the assessed groups: SD-MAP: (EVCO ( $9.27 \pm 0.54$ vs. $8.73 \pm 0.510)$; Placebo ( $8.90 \pm 0.65$ vs. $9.60 \pm 0.60)$; EVCO plus training (10.2 \pm 0.57 vs. $9.58 \pm 0.53)$ and Placebo plus training (9.40 \pm 0.64 vs. $9.56 \pm 0.60)$ ); and ARV-MAP: (EVCO (6.39 \pm 0.33 vs. $5.80 \pm 0.28$; Placebo (6.22 \pm 0.40 vs. $6.50 \pm 0.34)$; EVCO plus training ( $6.57 \pm 0.34$ vs. $6.07 \pm 0.29)$; and Placebo plus training ( $6.37 \pm 0.40$ vs. $6.71 \pm 0.33)$ ) (Figure 4$)$. 


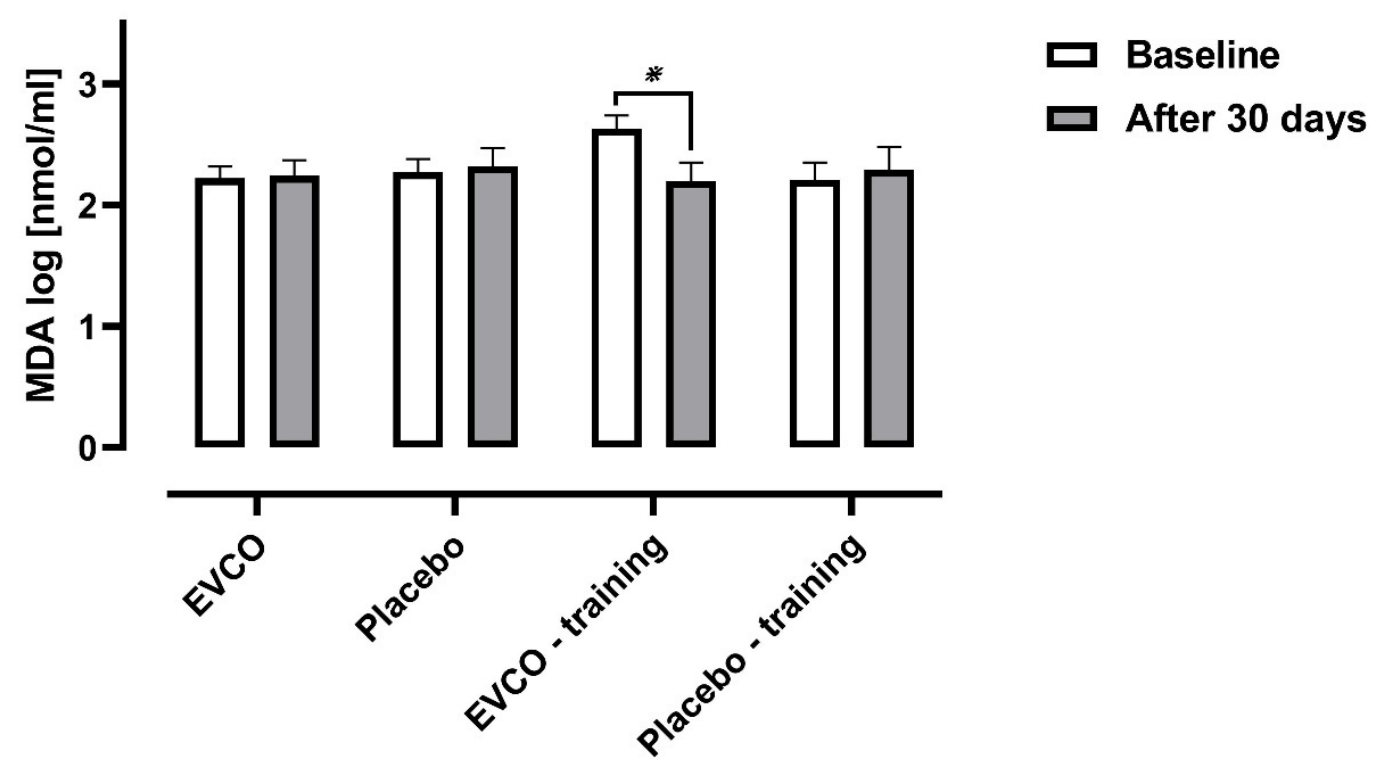

Figure 3. Comparison of serum malondialdehyde concentrations in hypertensive patients after 30 days of supplementation with EVCO or placebo, combined or not with aerobic physical training. One-way ANCOVA of repeated measures corrected for age, followed by a Bonferroni post-test $(n=45)$ : time factor $\left(p=0.559\right.$ and $\left.\eta^{2}=0.009\right)$; group factor $(p=0.644$ and $\left.\eta^{2}=0.04\right)$ and interaction factor $\left(p=0.015\right.$ and $\left.\eta^{2}=0.227\right)$. ${ }^{*}$ Post hoc for interaction: $p=0.001$ (EVCO-training group).

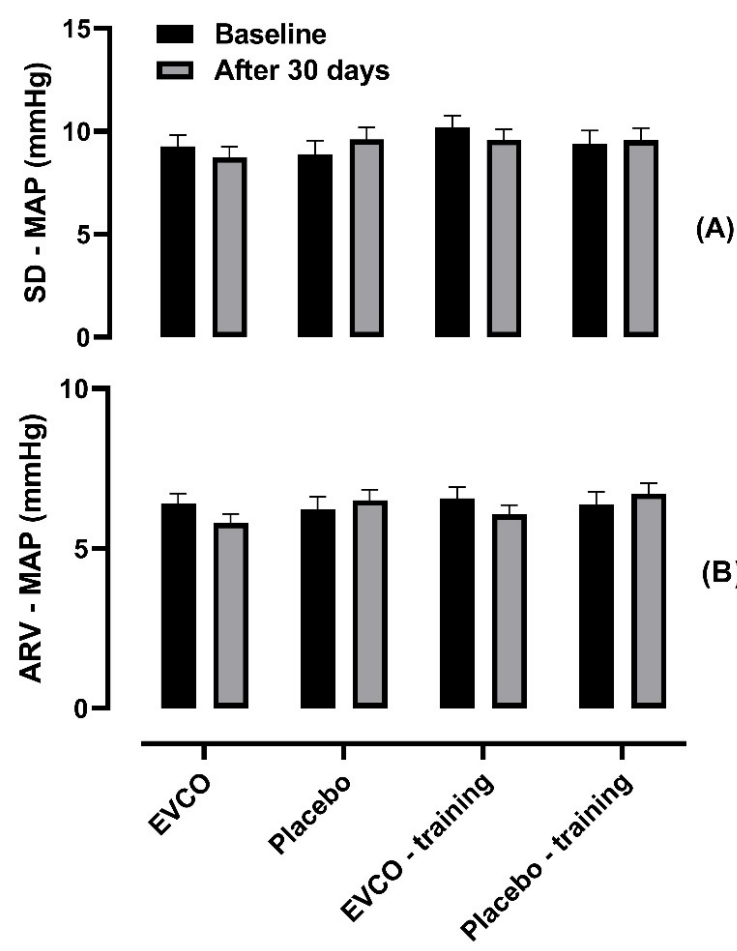

Figure 4. Comparison of the blood pressure variability in hypertensive patients after 30 days of supplementation with EVCO or placebo, combined or not with aerobic physical training. One-way ANCOVA of repeated measures corrected for age $(n=43)$. (A) SD-MAP: (Time factor $(p=0.696$ and $\left.\eta^{2} 0.004\right)$; group factor $\left(p=0.595\right.$ and $\left.\eta^{2}=0.048\right)$; and interaction factor $\left(p=0.233\right.$ and $\left.\eta^{2}=0.105\right)$. (B) ARV-MAP: (Time factor ( $p=0.848$ and $\left.\eta^{2} 0.001\right)$; group factor $\left(p=0.673\right.$ and $\eta^{2}=0.039$ ); and interaction factor $\left(p=0.434\right.$ and $\left.\eta^{2}=0.069\right)$. 


\section{Discussion}

Original preclinical studies provided evidence that both in natura coconut oil and its main isolated constituent, lauric acid, were able to evoke antihypertensive effect in spontaneously hypertensive rats and vasorelaxant effect in superior mesenteric artery, respectively $[13,14]$. It was also shown that these effects could be related to a reduction in oxidative stress in these experimental models. However, from a translational perspective, no study has been conducted to assess the possible effects of coconut oil in humans with hypertension.

Clinical studies with specific subpopulations and testing non-pharmacological alternatives are essential. Thus, considering the preliminary research, this was the first trial designed to assess the effects of EVCO in patients with systemic arterial hypertension. So, this study represents an effort to test an unknown outcome on the use of coconut oil in humans. In addition, we highlight the fact that the present study controlled precisely (through supplementation with capsules) the amount of EVCO effectively ingested. An important proportion of the studies that focus on this natural product did not properly control the amount of EVCO ingested; instead, it was included in meal preparation, without precise delimitations of its consumption $[25,26]$. Our study was placebo-controlled and used a biologically inert substance as a control intervention, the pharmaceutical starch. This is relevant because several studies have compared the use of coconut oil with other vegetable oils, which sometimes also have biological effects, causing complications in the interpretation of the results obtained $[27,28]$.

Regarding the primarily investigated outcome, there was no antihypertensive effect associated with supplementation with EVCO in patients with stage 1 arterial hypertension tested in this study, unlike what was evidenced in the preclinical study with an animal model of essential hypertension [13]. Clinically, it should be noted that the diagnostic parameter used in this study was consistent, since a 24-hour blood pressure monitoring technique was used. The ABPM is fundamental in the evaluation of the efficacy of antihypertensive drugs in clinical trials and, consequently, very useful in the clinical management of hypertension [29]. This type of cardiological evaluation has a high diagnostic power [30], as it eliminates stress-induced momentary hypertension, called white coat hypertension. Sometimes, an isolated outpatient measure may not reflect the patient's real blood pressure [31]. In some cases, a sympathetic discharge associated with the situation of being evaluated by a cardiologist is sufficient to induce a pressure response [32]. This evidence reinforces caution in issuing false-positive results. Finally, this monitoring reflects the pressure behavior during the entire $24 \mathrm{~h}$ period. On average, approximately 70 (seventy) blood pressure measurements are performed, without interference from the human factor during the checks, minimizing the measurement bias.

With regards to the difference in response evoked by coconut oil supplementation between pre-clinical and clinical studies, it is prudent to consider the distinctions inherent to each experimental model that was used in each study. The two studies involve specimens with different structure and metabolism and also with different experimental conditions. In the preclinical study, the dose of coconut oil administered was $2 \mathrm{~mL}$ per day for animals weighing between 200-300 g. Based on this dosage, if this was extrapolated for use in adult humans (average weight $70 \mathrm{Kg}$ ), an amount that would exceed $500 \mathrm{~mL}$ of EVCO per day would be necessary [33]. The dose used in this study $(10 \mathrm{~mL} /$ day $)$ was based on the study by [17] which proved to be safe, with no adverse effects recorded. [34] demonstrated that virgin coconut oil $(1.4 \mathrm{~mL} / \mathrm{kg}$ weight) prevents blood pressure elevation in rats fed palm oil. The experiment used 32 male Sprague-Dawley rats and measurements were performed every four weeks for a total period of 16 weeks by tail-cuff method. It is not clear that the beneficial effects attributed to coconut oil obtained in animal studies can be extended to humans. For example, Khaw et al. [28] compared three types of diets: EVCO, extravirgin olive oil and unsalted butter. The participants incorporated $50 \mathrm{~g}$ of the respective fats into their usual diet for a period of four weeks. These authors did not report any difference in pressure levels after the experimental period. On the other hand, Perona et al. [16] 
observed a reduction in systolic blood pressure levels in elderly hypertensive patients after using $60 \mathrm{~g}$ /day virgin olive oil for four weeks. Indeed, unlike what is observed in relation to coconut oil, Massaro et al. [35], through a distinguished review work, showed that there is relative similarity of effects between pre-clinical and clinical studies addressing the use of olive oil to treat hypertension. Summarizing, Wallace [25] performed a systematic review on the effects of coconut oil and concluded that the available evidence is sufficient only to encourage new studies with more methodological robustness. Another important aspect that deserves consideration is that, in order to avoid the confounding effects of medication, we opted for stage 1 hypertensive patients. Whether coconut oil may exert some beneficial effect on blood pressure of patients with higher blood pressure levels remains to be elucidated.

Although no effect on blood pressure was observed, a possible effect of EVCO on the autonomic function of patients was investigated. Two main factors motivated this experimental approach. First, in the pre-clinical study it was seen that, besides the antihypertensive activity, the supplementation with EVCO was associated with a reduction in oxidative stress and with an improvement in the baroreflex response in the treated animals [13]. Second, this interrelationship between a disturbance of blood pressure control mechanisms and the development of hypertension is widely reported [36]. A reduction in the effectiveness of control mechanisms can be expressed by increases in blood pressure oscillations over time [37]. It is important to emphasize that the autonomic function can also be explored through the analysis of blood pressure variability. This alternative constitutes a non-invasive tool capable of providing parameters related to autonomic activity based on blood pressure oscillations over time [38].

Blood pressure variability is not a physiological variable routinely accessed in clinical practice, although according to Hsu et al. [39], it is recognized as a prognostic factor independent of blood pressure level [24]. Evidence shows that the adverse cardiovascular consequences of high blood pressure may be the result of increased variability and not high blood pressure alone $[40,41]$. In addition, there is a strong association between increased $\mathrm{BP}$ variability and subclinical progression of target organ damage [42]. Two indexes of $\mathrm{BP}$ variability were used, the standard deviation and the average real variability. They are not redundant analyses, because according to Mena [24], ARV offers an additional reinforcement in the variability representation. Our results indicated no effect of ECVO supplementation on the variability indices evaluated. Furthermore, no effect interaction between the groups was observed, although a moderate effect size persists considering the average real variability. The analysis indicates that physical training did not prove to be determinant for this response. Although aerobic exercise is a useful complement to control hypertension, it does not necessarily affect blood pressure variability [43]. In addition, the most effective training protocols for lowering blood pressure levels are longer (minimum 8-12 weeks) [44]. The associative effect, i.e., the potentiating effect promoted by the supplementation with EVCO in combination with training, seen in the pre-clinical study [13], has not been fully reproduced in humans.

In addition, through the antioxidant potential of several coconut oil constituents $[45,46]$ and the relationship between reactive oxygen species and hypertension control mechanisms $[47,48]$ analyses were conducted to estimate the serum oxidative stress of hypertensive patients. This effect was evaluated by comparing the serum concentrations of MDA, a byproduct of lipid peroxidation, in different experimental conditions. As previously mentioned, this interaction between oxidative stress and damage to the autonomic function is well documented $[49,50]$ and increase in the variability has been linked to alterations in autonomic function, including sympathetic hyperactivity [51]. Following the findings of ineffectiveness obtained on the cardiovascular variables of blood pressure and blood pressure variability, it was found that nutritional supplementation with EVCO was not able to interfere with the oxidative stress accessed through the MDA. Only an isolated effect of the interaction was seen in the group supplemented with EVCO which also participated in the physical training program. Although this effect reproduces, at least in part, the possible 
amplifying response of EVCO combined with exercise training, it was obtained in a group that started from a higher baseline value of MDA.

In fact, the effectiveness of this antioxidant property inherent to EVCO has been attributed almost exclusively to animal models. Nevin and Ramajohan [9] showed that virgin coconut oil was related to an increase in the activity of the enzymes glutathione peroxidase, catalase and superoxide dismutase in organs such as liver, heart and kidneys. Famurewa et al. [8] demonstrated that this increase in the activity of hepatic catalase and superoxide dismutase (but not GPx) occurred in a concentration dependent on EVCO and that they were related to a decrease in MDA. This response was also observed in homogenate of rat heart muscle [10]. Studies in humans focusing on the antioxidant property of coconut oil are rare and less consistent. Sabitha et al. [52], for example, found no significant differences between individuals treated with coconut or sunflower oil in relation to oxidative stress. Additionally, the results indicated that physical exercise was not able to promote significant changes in oxidative stress after 30 days. It seems that this relationship between exercise and oxidative stress is complicated and can be modulated in several levels of intensity, type and duration of training [53,54]. Regarding other possible sources of exogenous antioxidants offered by the diet during the experimental period that could eventually have interfered with the responses discussed in this study, it should be noted that the nutritional follow-up implemented represented an additional factor to reinforce the evidence presented.

In conclusion, the supplementation with EVCO did not have an antihypertensive effect in patients with stage 1 hypertension. It also showed no effectiveness on blood pressure variability and oxidative stress levels in humans. Thus, although coconut oil supplementation $(10 \mathrm{~mL} /$ day) was shown to be safe as a nutritional approach and without significant impacts on the caloric load intake, it was not able to reproduce the effects obtained in an experimental model of hypertension when translated to hypertensive patients. Finally, it should be ratified that complementary studies are necessary to determine if doses different from the current trial can evoke additional or diverse effects.

Author Contributions: V.A.B. conceived the study. F.A.O.J. and C.R.R. performed the experiments. Y.d.O. reviewed the nutritional records. M.A.V.B. performed cardiologic consultations. A.S.S. contributed to the physical training program. M.S.B.S. enabled the analysis of blood pressure variability. V.J.B.M. contributed in the statistical analysis. C.M.B. and F.A.O.J. drafted the manuscript. All authors analyzed the data and revised the manuscript critically. All authors have read and agreed to the published version of the manuscript.

Funding: This research was funded by the National Council for the Development of Science and Technology (CNPq, 429767/2016-1 and 304718/2011-4) and by the Paraiba State Research Foundation (FAPESQ, ID: 007/2019 FAPESQ-PB-MCT/CNPq).

Institutional Review Board Statement: The study was conducted according to the guidelines of the Declaration of Helsinki, and approved by the Ethics Committee of the University Hospital at the Federal University of Paraiba (protocol code 1.523.128/2016 approved on 04/30/2016). Informed consent was obtained from all subjects involved in the study. All data regarding this study are available upon request to the corresponding author by the e-mail: valdir@cbiotec.ufpb.br.

Acknowledgments: Authors want to thank José Cazuza F Júnior for the support in statistics and additional thanks to Alex A. Araújo for the help in the tabulation for the analysis of blood pressure variability.

Conflicts of Interest: The authors declare no conflict of interest.

\section{References}

1. Benjamin, E.J.; Virani, S.S.; Callaway, C.W.; Chamberlain, A.M.; Chang, A.R.; Cheng, S.; Chiuve, S.E.; Cushman, M.; Delling, F.N.; Deo, R.; et al. Heart Disease and Stroke Statistics-2018 Update: A Report from the American Heart Association. Circulation 2018, 137, e67-e492. [CrossRef]

2. Mittal, B.V.; Singh, A.K. Hypertension in the developing world: Challenges and opportunities. Am. J. Kidney Dis. 2010, 55, 590-598. [CrossRef] [PubMed] 
3. Massa, N.M.; Silva, A.S.; Toscano, L.T.; Silva, J.D.; Persuhn, D.C.; Gonçalves, M.A.C. Watermelon extract reduces blood pressure but does not change sympathovagal balance in prehypertensive and hypertensive subjects. Blood Press. 2016, 25, 244-248. [CrossRef]

4. Toscano, L.T.; da Silva, C.S.; de Almeida, A.E.; Santos, A.a.C.; Silva, A.S. Chia flour supplementation reduces blood pressure in hypertensive subjects. Plant Foods Hum. Nutr. 2014, 69, 392-398. [CrossRef] [PubMed]

5. Devarajan, S.; Singh, R.; Chatterjee, B.; Zhang, B.; Ali, A. A blend of sesame oil and rice bran oil lowers blood pressure and improves the lipid profile in mild-to-moderate hypertensive patients. J. Clin. Lipidol. 2016, 10, 339-349. [CrossRef]

6. DebMandal, M.; Mandal, S. Coconut (Cocos nucifera L.: Arecaceae): In health promotion and disease prevention. Asian Pac. J. Trop. Med. 2011, 4, 241-247. [CrossRef]

7. Chinwong, S.; Chinwong, D.; Mangklabruks, A. Daily Consumption of Virgin Coconut Oil Increases High-Density Lipoprotein Cholesterol Levels in Healthy Volunteers: A Randomized Crossover Trial. Evid. Based Complement. Alternat. Med. 2017, 2017, 7251562. [CrossRef] [PubMed]

8. Famurewa, A.C.; Ekeleme-Egedigwe, C.A.; Nwali, S.C.; Agbo, N.N.; Obi, J.N.; Ezechukwu, G.C. Dietary Supplementation with Virgin Coconut Oil Improves Lipid Profile and Hepatic Antioxidant Status and Has Potential Benefits on Cardiovascular Risk Indices in Normal Rats. J. Diet. Suppl. 2018, 15, 330-342. [CrossRef]

9. Nevin, K.G.; Rajamohan, T. Virgin coconut oil supplemented diet increases the antioxidant status in rats. Food Chem. 2006. [CrossRef]

10. Subermaniam, K.; Saad, Q.H.; Das, S.; Othman, F. Virgin Coconut Oil (VCO) Decreases the Level of Malondialdehyde (MDA) in the Cardiac Tissue of Experimental Sprague-Dawley Rats Fed with Heated Palm O I Request PDF. J. Med. Bioeng. 2014, 3. [CrossRef]

11. Eyres, L.; Eyres, M.F.; Chisholm, A.; Brown, R.C. Coconut oil consumption and cardiovascular risk factors in humans. Nutr. Rev. 2016, 74, 267-280. [CrossRef]

12. Sacks, F.M. Coconut Oil and Heart Health: Fact or Fiction? Circulation 2020, 141, 815-817. [CrossRef] [PubMed]

13. Alves, N.F.; Porpino, S.K.; Monteiro, M.M.; Gomes, E.R.; Braga, V.A. Coconut oil supplementation and physical exercise improves baroreflex sensitivity and oxidative stress in hypertensive rats. Appl. Physiol. Nutr. Metab. 2015, 40, 393-400. [CrossRef]

14. Alves, N.F.; de Queiroz, T.M.; de Almeida Travassos, R.; Magnani, M.; de Andrade Braga, V. Acute Treatment with Lauric Acid Reduces Blood Pressure and Oxidative Stress in Spontaneously Hypertensive Rats. Basic Clin. Pharmacol. Toxicol. 2017, 120, 348-353. [CrossRef]

15. Malachias, M.V. 7th Brazilian Guideline of Arterial Hypertension: Presentation. Arq. Bras. Cardiol. 2016, 107, XV-XIX. [CrossRef]

16. Perona, J.S.; Canizares, J.; Montero, E.; Sanchez-Dominguez, J.M.; Catala, A.; Ruiz-Gutierrez, V. Virgin olive oil reduces blood pressure in hypertensive elderly subjects. Clin. Nutr. 2004, 23, 1113-1121. [CrossRef] [PubMed]

17. Law, K.S.; Azman, N.; Omar, E.A.; Musa, M.Y.; Yusoff, N.M.; Sulaiman, S.A.; Hussain, N.H. The effects of virgin coconut oil (VCO) as supplementation on quality of life (QOL) among breast cancer patients. Lipids Health Dis. 2014, 13, 139. [CrossRef] [PubMed]

18. Pescatello, L.S.; MacDonald, H.V.; Lamberti, L.; Johnson, B.T. Exercise for Hypertension: A Prescription Update Integrating Existing Recommendations with Emerging Research. Curr. Hypertens. Rep. 2015, 17, 87. [CrossRef]

19. George, J.D.; Vehrs, P.R.; Allsen, P.E.; Fellingham, G.W.; Fisher, A.G. VO2max estimation from a submaximal 1-mile track jog for fit college-age individuals. Med. Sci. Sports Exerc. 1993, 25, 401-406. [CrossRef]

20. Karvonen, M.J. The effects of training on heart rate: A longitudinal study. Ann. Med. Exp. Biol. Fenn. 1957, 35, 307-315. [PubMed]

21. Borg, G.A. Perceived exertion. Exerc. Sport Sci. Rev. 1974, 2, 131-153. [CrossRef] [PubMed]

22. Ohkawa, H.; Ohishi, N.; Yagi, K. Assay for lipid peroxides in animal tissues by thiobarbituric acid reaction. Anal. Biochem. 1979, 95, 351-358. [CrossRef]

23. Alessi, A.; Brandão, A.A.; Pierin, Â.; Feitosa, A.M.; Machado, C.A.; Forjaz, C.L.; Atie, C.S.; Giorgi, D.M.A.; Mion, D., Jr.; Rosa, E.C. IV Guideline for Ambulatory Blood Pressure Monitoring-II Guideline for Home Blood Pressure Monitoring IV ABPM/II HBPM. Arq. Bras. Cardiol. 2005, 85, 1-18.

24. Mena, L.J.; Felix, V.G.; Melgarejo, J.D.; Maestre, G.E. 24-Hour Blood Pressure Variability Assessed by Average Real Variability: A Systematic Review and Meta-Analysis. J. Am. Heart Assoc. 2017, 6, e006895. [CrossRef] [PubMed]

25. Wallace, T.C. Health Effects of Coconut Oil-A Narrative Review of Current Evidence. J. Am. Coll. Nutr. 2019, 38, 97-107. [CrossRef] [PubMed]

26. Assunção, M.L.; Ferreira, H.S.; dos Santos, A.F.; Cabral, C.R.; Florêncio, T.M. Effects of dietary coconut oil on the biochemical and anthropometric profiles of women presenting abdominal obesity. Lipids 2009, 44, 593-601. [CrossRef]

27. Palazhy, S.; Kamath, P.; Vasudevan, D.M. Dietary Fats and Oxidative Stress: A Cross-Sectional Study Among Coronary Artery Disease Subjects Consuming Coconut Oil/Sunflower Oil. Indian J. Clin. Biochem. 2018, 33, 69-74. [CrossRef] [PubMed]

28. Khaw, K.T.; Sharp, S.J.; Finikarides, L.; Afzal, I.; Lentjes, M.; Luben, R.; Forouhi, N.G. Randomised trial of coconut oil, olive oil or butter on blood lipids and other cardiovascular risk factors in healthy men and women. BMJ Open 2018, 8, e020167. [CrossRef] [PubMed]

29. Mancia, G.; Fagard, R.; Narkiewicz, K.; Redón, J.; Zanchetti, A.; Böhm, M.; Christiaens, T.; Cifkova, R.; De Backer, G.; Dominiczak, A.; et al. 2013 ESH/ESC Guidelines for the management of arterial hypertension: The Task Force for the management of arterial hypertension of the European Society of Hypertension (ESH) and of the European Society of Cardiology (ESC). J. Hypertens. 2013, 31, 1281-1357. [CrossRef] 
30. Ghazi, L.; Pajewski, N.M.; Rifkin, D.E.; Bates, J.T.; Chang, T.I.; Cushman, W.C.; Glasser, S.P.; Haley, W.E.; Johnson, K.C.; Kostis, W.J. Effect of Intensive and Standard Clinic-Based Hypertension Management on the Concordance Between Clinic and Ambulatory Blood Pressure and Blood Pressure Variability in SPRINT. J. Am. Heart Assoc. 2019, 8, e011706. [CrossRef] [PubMed]

31. Grossman, E. Ambulatory blood pressure monitoring in the diagnosis and management of hypertension. Diabetes Care 2013, 36, S307-S311. [CrossRef] [PubMed]

32. Grassi, G.; Turri, C.; Vailati, S.; Dell'Oro, R.; Mancia, G. Muscle and skin sympathetic nerve traffic during the "white-coat" effect. Circulation 1999, 100, 222-225. [CrossRef] [PubMed]

33. Reagan-Shaw, S.; Nihal, M.; Ahmad, N. Dose translation from animal to human studies revisited. FASEB J. 2008, 22, 659-661. [CrossRef]

34. Nurul-Iman, B.S.; Kamisah, Y.; Jaarin, K.; Qodriyah, H.M. Virgin coconut oil prevents blood pressure elevation and improves endothelial functions in rats fed with repeatedly heated palm oil. Evid. Based Complement. Alternat. Med. 2013, $2013,629329$. [CrossRef] [PubMed]

35. Massaro, M.; Scoditti, E.; Carluccio, M.A.; Calabriso, N.; Santarpino, G.; Verri, T.; De Caterina, R. Effects of Olive Oil on Blood Pressure: Epidemiological, Clinical, and Mechanistic Evidence. Nutrients 2020, 12, 1548. [CrossRef] [PubMed]

36. Takagi, T.; Ohishi, M.; Ito, N.; Kaibe, M.; Tatara, Y.; Terai, M.; Shiota, A.; Hayashi, N.; Rakugi, H.; Ogihara, T. Evaluation of morning blood pressure elevation and autonomic nervous activity in hypertensive patients using wavelet transform of heart rate variability. Hypertens. Res. 2006, 29, 977-987. [CrossRef]

37. Mancia, G.; Bombelli, M.; Facchetti, R.; Madotto, F.; Corrao, G.; Trevano, F.Q.; Grassi, G.; Sega, R. Long-term prognostic value of blood pressure variability in the general population: Results of the Pressioni Arteriose Monitorate e Loro Associazioni Study. Hypertension 2007, 49, 1265-1270. [CrossRef]

38. Lodhi, H.A.; Peri-Okonny, P.A.; Schesing, K.; Phelps, K.; Ngo, C.; Evans, H.; Arbique, D.; Price, A.L.; Vernino, S.; Phillips, L.; et al. Usefulness of Blood Pressure Variability Indices Derived From 24-Hour Ambulatory Blood Pressure Monitoring in Detecting Autonomic Failure. J. Am. Heart Assoc. 2019, 8, e010161. [CrossRef]

39. Hsu, P.F.; Cheng, H.M.; Wu, C.H.; Sung, S.H.; Chuang, S.Y.; Lakatta, E.G.; Yin, F.C.; Chou, P.; Chen, C.H. High Short-Term Blood Pressure Variability Predicts Long-Term Cardiovascular Mortality in Untreated Hypertensives But Not in Normotensives. Am. J. Hypertens. 2016, 29, 806-813. [CrossRef]

40. Rothwell, P.M. Does blood pressure variability modulate cardiovascular risk? Curr. Hypertens. Rep. 2011, 13, 177-186. [CrossRef]

41. Floras, J.S. Blood pressure variability: A novel and important risk factor. Can. J. Cardiol. 2013, 29, 557-563. [CrossRef] [PubMed]

42. Parati, G.; Ochoa, J.E.; Lombardi, C.; Bilo, G. Assessment and management of blood-pressure variability. Nat. Rev. Cardiol. 2013, 10, 143-155. [CrossRef] [PubMed]

43. Pagonas, N.; Dimeo, F.; Bauer, F.; Seibert, F.; Kiziler, F.; Zidek, W.; Westhoff, T.H. The impact of aerobic exercise on blood pressure variability. J. Hum. Hypertens. 2014, 28, 367-371. [CrossRef] [PubMed]

44. Baghaiee, B.; Karimi, P.; Ebrahimi, K.; Dabagh Nikoo Kheslat, S.; Sadeghi Zali, M.H.; Daneshian Moghaddam, A.M.; Sadaghian, M Effects of a 12-week aerobic exercise on markers of hypertension in men. J. Cardiovasc. Thorac. Res. 2018, 10, 162-168. [CrossRef]

45. Marina, A.M.; Che Man, Y.B.; Amin, I. Chemical Properties of Virgin Coconut Oil I SpringerLink. J. Am. Oil Chem. Soc. 2009, 86, 301-307. [CrossRef]

46. Vysakh, A.; Ratheesh, M.; Rajmohanan, T.P.; Pramod, C.; Premlal, S.; Sibi, P.I. Polyphenolics isolated from virgin coconut oil inhibits adjuvant induced arthritis in rats through antioxidant and anti-inflammatory action. Int. Immunopharmacol. 2014, 20, 124-130. [CrossRef] [PubMed]

47. Briones, A.M.; Touyz, R.M. Oxidative stress and hypertension: Current concepts. Curr. Hypertens. Rep. 2010, 12, 135-142. [CrossRef]

48. Baradaran, A.; Nasri, H.; Rafieian-Kopaei, M. Oxidative stress and hypertension: Possibility of hypertension therapy with antioxidants. J. Res. Med. Sci. 2014, 19, 358-367.

49. Bruno, R.M.; Ghiadoni, L. Polyphenols, Antioxidants and the Sympathetic Nervous System. Curr. Pharm. Des. 2018, 24, 130-139. [CrossRef]

50. Salim, S. Oxidative Stress and the Central Nervous System. J. Pharmacol. Exp. Ther. 2017, 360, 201-205. [CrossRef]

51. Zuern, C.S.; Rizas, K.D.; Eick, C.; Stoleriu, C.; Bunk, L.; Barthel, P.; Balletshofer, B.; Gawaz, M.; Bauer, A. Effects of renal sympathetic denervation on 24-hour blood pressure variability. Front. Physiol. 2012, 3, 134. [CrossRef] [PubMed]

52. Sabitha, P.; Vaidyanathan, K.; Vasudevan, D.M.; Kamath, P. Comparison of lipid profile and antioxidant enzymes among south Indian men consuming coconut oil and sunflower oil. Indian J. Clin. Biochem. 2009, 24, 76-81. [CrossRef] [PubMed]

53. Ristow, M.; Zarse, K.; Oberbach, A.; Klöting, N.; Birringer, M.; Kiehntopf, M.; Stumvoll, M.; Kahn, C.R.; Blüher, M. Antioxidants prevent health-promoting effects of physical exercise in humans. Proc. Natl. Acad. Sci. USA 2009, 106, 8665-8670. [CrossRef] [PubMed]

54. Farinha, J.B.; Steckling, F.M.; Stefanello, S.T.; Cardoso, M.S.; Nunes, L.S.; Barcelos, R.P.; Duarte, T.; Kretzmann, N.A.; Mota, C.B.; Bresciani, G.; et al. Response of oxidative stress and inflammatory biomarkers to a 12-week aerobic exercise training in women with metabolic syndrome. Sports Med. 2015, 1, 1-10. [CrossRef] [PubMed] 